\title{
An Insight of Present Goat Farming Situation- A Review
}

\author{
Sukhwinder Singh ${ }^{1}$, Rajesh Kasrija ${ }^{2^{*}}$ and Parminder Singh $^{3}$ \\ Department of Veterinary and Animal Husbandry Extension Education, Guru Angad Dev \\ Veterinary and Animal Sciences University, Ludhiana, India \\ *Corresponding author
}

K e y w o r d s
Goat Farming,
Goat rearing,
Livestock

\section{Introduction}

The archaeological evidences had indicated association of goats with man in a symbiotic relationship for up to 10,000 years (Ensminger and Parker, 1986). This long association between goat and human suggests about the variety of functions the goat can provide. Goats had been reported to be important to food and economic securities of developing regions for countless years, and their contributions to economic returns in developed countries has been rising as well (Sahlu and Goetsch, 2005).
In India, over $75 \%$ of livestock resources were controlled by smallholders and landless, farmer together (Birthal and Taneja, 2006). The farmers and pastoralists are increasingly relying on goats as means of survival and a way of boosting their income (Peacock, 2005). The households cultivating less than 2.0 ha of land (marginal and small) are the custodian of more than $76 \%$ of the total goats in the country (Singh et al., 2018).

Goat rearing plays a vital role in food and economic security of rural people, especially landless, marginal and small farmers 
(Chander and Rathod, 2015). Goats act as a ready to use economic asset at time of crisis among rural farmers (Lebbie, 2004) by providing meat, milk, hide, manure and wool. Goats provide their owners with a broad range of products and socio-economic services and have played an important role in the social life of many people being used as gifts, dowry, in religious rituals and rites of passage (Peacock, 1996).

According to 20th Indian Livestock Census 2019, the Goat population in India is 148.88 million showing an increase of $10.1 \%$ over the previous census. The male goat population is 32.10 million showing a decrease of $14.65 \%$, while female goat population is 116.78 million showing an increase of $19.71 \%$ and number of goats in milk is 41.83 million showing an increase of $15.38 \%$ over the previous census in India. In Punjab, the total goat population is $3.48 \mathrm{lakh}$, while in previous census the number was 3.27 lakh. (http://dadf.gov.in/sites/default/ filess/ Key\%20Results\%2BAnnexure\%2018.10.201 9.pdf). This clearly indicates that number of goats in Punjab as well as in India have increased.

Goats are reported to be more economical than cattle and sheep under natural grazing/ browsing (Sharma and Jindal, 2008). Even, the Goat rearing is reported to be a economically viable and highly profitable commercial enterprise under semi-intensive system of management (Kumar and Jain, 2002). Kumar, (2007) reported that goat enterprise has shown promise of its successful intensification and commercialization because of shrinking of resources for extensive grazing. Several large and progressive farmers, businessman and industrialists have adopted commercial goat farming. The entry of large farmers, who have better access to technical knowledge, resources and market, into this activity would help in realizing the potential of goat enterprise. Goat rearing has been found equally rewarding under both intensive and semi-intensive systems of management.

Also, the goat rearing has distinct economic and managerial advantages over other livestock because of less initial investment, low input requirement, shorter generation interval and ease in marketing Goat rearing can provide part time self-employment without affecting the main occupation for small and marginal farmers. Goat has been playing multiple role in livelihood of the rural people by providing income, employment, nutrition, supporting crop production and risk aversion in case of crop failure. Landless men and women are increasingly relying on goat keeping for their socio-economic upliftment (Singh et al., 2018). The families which had more number of children were more inclined to keep goats as the children could be used for taking goats to grazing on fallow land, harvested fields, alongside roads and other uncultivated areas (Arya and Chander, 2000).

In the North West province of South Africa, goats in this area are kept for social reasons and for food security. The commercial production of goats marketed at an optimum age could potentially improve the economy of small farmers (Lusweti, 2000). In South and South East Asia, goats were largely concentrated in the rain-fed lowlands, including the semi-arid and arid agroecological zones and the upland areas in mainly mixed farming situations (Devendra, 2001). Braker et al., (2002) reported that in three communities in South Africa, namely Jericho (Northwest Province), Bolahlakgomo (Northern Province) and Schoonoord (Northern Province), traditional purposes and meat consumption were important reasons for keeping goats. Other reasons mentioned were used to characterize the systems and were commercially-orientated in Jericho, social 
reasons in Bolahlakgomo and of a supportive nature in Schoonoord. The average herd size was 16.2 animals in Jericho, 7.7 animals in Bolahlakgomo and 40.1 animals in Schoonoord.

In Nepal, Goat is the most popular small ruminant which can be handled by women and children in absence of young male members. It not only provides employment to the rural poor, it also acts as a security against the crop failure and has religious importance. It require less capital investment and feeding costs. It has higher reproductive rates due to shorter breeding interval and high prolific Since supply is far behind the demand which is fulfilled through import, sufficient effort is necessary to increase the goat production in order to reduce the import and improve trade deficit of the country (Neupane et al., 2018).

In North Indian plains, mostly Muslims and landless laborers, small, marginal farmers were the group having interest in goat keeping (Arya and Chander, 2000).

In semi-arid parts of India, goats play a significant role in food and nutritional security of the family. Goat rearing utilizes the labor, which has negligible opportunity cost, and generates income and employment. Importantly, it helps in the empowerment of poor rural women by providing them employment and to some extent financial autonomy. Goats of rural poor were mainly dependent on common property resources (CPRs), which have been declining in the recent past (Kumar and Deoghare 2002).

In Ranchi district, average goat enterprise contributed about $30 \%$ to the total gross income from livestock. Goats were reared by all categories of tribal people irrespective of socioeconomic status. Goat farming was reported to be a low risk activity and provides significant employment (Singh, 2002).
Kumar et al., (2006) reported that in Uttar Pradesh (irrigated) and Rajasthan (unirrigated), the goats were found to have contributed significantly to family's' livelihood security. The families of goat keepers had access to goat milk for a period of about 190 to 264 days in a year. The net annual income was estimated to be Rs. 1302 to Rs. 1873 per goat per annum. The goats alone contributed 49 to 86 per cent to the households' total income. Sharma et al., (2007) reported that in Nathdwara, Vallabhnagar, Railmagra and Devgarh areas of Rajasthan that majority of goat rearers belonged to middle age group and other backward caste category. The literacy rate of goat keepers was $40 \%$. Most of $(66 \%)$ goat keepers were dependent on Agriculture and Animal Husbandry for livelihood and had annual income between Rs. 15,000-30,000. The majority of goat keepers had land holding size between 0.5-1.0 hectare. The overall average goat holding of goat keepers was 22.96 goats and average flock size for landless farmers was 19.54.

Tanwar et al., (2008) reported that in the tribal area of Udaipur district of Rajasthan, majority of the respondents belonged to 31-50 years of age group, schedule tribe, illiterate, medium size family and having small land holding. In Maharastra, Sangamneri goats were reared by majority of landless labourers under stall-fed conditions (Lalwar et al., 2009). In Uttar Pradesh, only the landless, agricultural wage earners and marginal and small farmers were involved in goat rearing. However, in Rajasthan, where drought is frequent, goat rearing was adopted by all categories of farmers. Most farmers practiced goat rearing for their subsistence and hence seldom calculated the cost of production (Kumar et al., 2010).

In Tripura State, poor people were mostly engaged in Black Bengal goat rearing. 
Farmers kept goats in house made up of bamboo. Major constraint's hindering in Black Bengal goat rearing observed by the farmers were non-availability of round the year feed and fodder supply and lack of proper treatment and vaccination (Dandapat $e t$ al., 2009).

In north Gujarat, the average annual recurring expenditure and net profit per lactating doe was Rs 524.64 and Rs 668.81, respectively. The maximum net receipt of Rs 814.38 per lactating goat was observed in very large sized flocks $(>70)$. Overall annual net profit per household in the survey area was Rs $18,162.46$, which varied from Rs $3,179.87$ to Rs 51,381.59 depending on the size of the flock. Goat farming under the traditional extensive low-input production system was reported to be a profitable enterprise and offers livelihood security particularly for landless, small and marginal farmers, and the rural poor. Profitability can be further improved by increasing the size of the flock with approximately the same utilization of labour as with a small sized flock (Singh et al 2009). In Karnataka, $46.66 \%$ of the respondents accrued income between Rs. 1,300 and Rs. 5,866 and 30\% respondents accrued between Rs.5,867 and Rs.10,432 from small ruminants and remaining respondents (23.33\%) between Rs.10,433 and Rs.15,000 per annum (Ramesh, 2009).

In Uttar Pradesh, large herd size group of goat keepers achieved higher profits than small and medium herd size groups both in barbari and local breed group of goats. The overall net annual income per goat was worked out to be Rs. 1183.66 in barbari breed and Rs. 894.06 in local breed of goats. The annual income of barbari breed of different herd size groups was higher in comparison to local breed of goats. This shows that the improved breed of barbari goats have positive impact on the income of goat keepers (Singh et al., 2011).
In Punjab, most of the goat farmers $(62.50 \%)$ were between age group 31-60 years. Very few $(0.83 \%)$ goat farmers were female. The education level of most of the goat farmers was not up to mark being $52.08 \%$ illiterate. The main occupation of majority $(78.32 \%)$ of farmers engaged in rearing goats is goat farming. $50 \%$ farmers had medium size and joint families. Majority $(74.58 \%)$ of goat farmers were landless. $47.50 \%$ goat farmers belonged to schedule caste, followed by $33.75 \%$ belonging to general caste, $11.25 \%$ belonging to backward class and $7.5 \%$ belonging to other backward classes. Age, education, main occupation, family size, family type and land holding were significantly correlated $\{$ Singh et al., 2020(d)\}.

In southern Karnataka, the landholdings of 12 acres and more than 2 acres were with 46.05 $\%$ and $37.21 \%$ of the goat rearers respectively, while the remaining (16.74\%) goat rearers were landless labourers. The flock size ranged from 27 to 40 which were not of any distinct breed. The average number of does, bucks and kids was $17.48 \pm 12.77$, $5.62 \pm 4.63$ and $8.75 \pm 5.26$, respectively, with the Does: Buck: Kids ratio being approximately 3: 1: 2 (Jayashree et al., 2014). In Amravati district of Maharashtra, socioeconomic status of goat farmers was reported to be major hindrance in adoption of improved goat farming practices (Koli and Koli., 2016).

Majority of goat-keepers in Bundelkhand region of Uttar Pradesh belonged to the backward social community (54\%), followed by schedule caste $(37 \%)$ and general category (9\%). Goat was kept by all categories of farmers though its contribution to income was more among marginal and small farmers in both the districts. Goats contribute 14-16 per cent in average household income besides providing nutrition (milk) to family (Singh et al., 2013). 
Annual income, credit acquisition, occupation, land holding, knowledge about recommended goat rearing practices, cosmopoliteness, extension contact, number of animal and housing pattern showed significant contribution in the adoption of recommended goat rearing practices in Mahasamund district of Chhattisgarh (Yadaw and Sharma, 2012).

For small-scale Malabari goat production units in Kerala, cost and return analysis showed that the major expenditure was on feed and fodder, and veterinary expenses were secondary. The chief returns were the sale of live animals, milk and manure. Individual farm technical efficiency ranged from 0.34 to 0.97 with a mean of 0.88 . The technical efficiency was significantly affected by herd size (number of animal units) and centre (locality of farm), but not by sex of farmer, education, land size and family size. Technical efficiency decreased as herd size increased; half the units with five or more adult animals had technical efficiency below $60 \%$ (Alex et al., 2013).

In Wayanad district of Kerala, very few women had correct knowledge about important aspects of breeding, housing and deworming of goats. Nearly three fourths of them had correct knowledge about vaccination against foot and mouth disease (George et al., 2010). The knowledge level of women about goat husbandry practice/technology was found inadequate. They must be trained in appropriate technologies and skills for efficient management of goat enterprise (Gautam, 1998). Farm women wanted to know more about treatment of animals, controlling external parasites, controlling internal parasites and animal breeding. $20 \%$ farm women rely on friends, husband and neighbors for acquisition of information, $17.6 \%$ rely on listening to radio and television, $20 \%$ rely on meeting extension personnel, $16 \%$ rely on meeting educated people, $14.4 \%$ rely on recourse to opinion leaders to seek information in respect of dairy farming and home management (Rezvanfar et al., 2007).

Poor productivity and lack of scientific knowledge about goat farming proves to be the lacunae behind goat production in rural India (Mohan et al., 2009). In West Bengal and Uttar Pradesh, majority of the goat owners had medium level of knowledge about healthcare management practices. Education, landholding, mass media exposure, formal interpersonal contact and social participation are significantly and positively correlated with knowledge level. Mass media exposure, education, informal interpersonal contact, landholding and flock size were the main contributing factors to farmers' knowledge level in healthcare management practices (Roy and Tiwari, 2017). Satyanarayan and Jagadeeswary, (2010) reported that in Bangalore North taluka, three fourths $(80.00 \%)$ of sheep and goat farmers possessed low knowledge followed by medium $(18.00 \%)$ and high $(2.00 \%)$ knowledge levels on recommended management practices on sheep and goat rearing. Low population of sheep and goat could be the reason for lack of interest in seeking knowledge on management practices.

Debele et al., (2013) reported that in Adami Tulu Jido kombolcha district of Ethiopia, 20\% of the respondents did not know to let the newly born kids to feed colostrums within 3672 hours whereas majority of them $(80 \%)$ know to suckle the newly born kids in order to feed colostrums. Almost half of the respondent of the study areas did not separate sick animals from normal animals. Jayashree et al., (2014) reported in study on 215 randomly selected goat flocks of selected villages from the four agro-climatic zones 
viz., Eastern dry zone (EDZ), Central dry zone (CDZ), Southern dry zone (SDZ) and Southern transition zone (STZ) of Southern Karnataka that all the farmers were aware of the essentiality of vaccination and deworming for which they depended on Goverenment Veterinary dispensaries.

In Punjab, knowledge about breed specific character, age of sexual maturity in does, age of sexual maturity in bucks, heat detection and heat signs were possessed by $45.00 \%$, $40.42 \%, 45.00 \%, 34.58 \%$ and $54.17 \%$ goat farmers respectively.

Knowledge about methods of mating, male: female for breeding, age of castration, gestation period, methods of pregnancy diagnosis, care during pregnancy and complication during pregnancy was with $32.08 \%, 40.00 \%, 43.75 \%, 83.33 \%, 20.83 \%$, $40.83 \%$ and $33.75 \%$ goat farmer.

Knowledge about signs of kidding, complication during kidding, care after kidding, lactation period in doe, kidding interval, sexually transmissible diseases, causes of pregnancy loss, reproductive disorder and best breeding season was possessed by $39.17 \%, 32.50 \%, 34.17 \%$, $33.75 \%, 30.00 \%, 24.58 \%, 21.25 \%, 19.58 \%$ and $49.58 \%$ goat farmers. The mean awareness of goat farmers about breeding practices in Punjab was $38.02 \%$ \{Singh et al., $2020(b)\}$.

Singh et al., 2020 (a) reported that in Punjab, knowledge about stall feeding of goat, types of feed, feeding schedule, mineral mixture, ration formulation, additional feed supplement, silage \& hay making, cleaning of utensils and provision of fresh \& clean water was possessed by $40.00 \%, 40.42 \%, 30.42 \%$, $35.83 \%, 29.17 \%, 28.75 \%, 37.08 \%, 57.50$ $\%$ and $47.08 \%$ respectively. The mean knowledge of goat farmers about feeding practices in Punjab was $38.47 \%$. There were significant differences between feeding knowledge scores $(\mathrm{P}<0.01)$ of goat farmers in different agro-climatic zones of Punjab. The knowledge level about feeding practices in different zones was low to medium.

Knowledge about vaccination schedule, vaccine, deworming schedule, ectoparasite control, mastitis, cleaning of udder, teat dipping was with $38.33 \%, 26.25 \%, 51.25 \%$, $45.42 \%, 47.50 \%, 48.33 \%$ and $40.00 \%$ goat farmers respectively in Punjab. $38.75 \%$, $30.00 \%$, 44.17\%, 32.50\%, 43.75\%, 44.17\%, $44.58 \%, 39.58 \%, 45.83 \%$ and $41.67 \%$ goat farmers possessed knowledge about common diseases, zoonotic disease, record keeping, management during adverse climate, method of milking, cleaning of milking utensil, colostrum feeding, weaning of kid, ligation \& disinfection of naval cord and kid deworming respectively.

Knowledge about disbudding, castration, tagging, hoof trimming, age estimation by dentition, quarantine and proper disposal of dead goat was with $45.83 \%, 37.08 \%, 32.50 \%$, $34.17 \%, 21.25 \%, 19.58 \%$ and $21.67 \%$ goat farmers respectively. The mean awareness of goat farmers about health and management practices in Punjab was $38.09 \%$ and was in medium category $\{$ Singh et al., 2020 (c) $\}$.

Knowledge about type of housing, space requirements, separate shed, location \& orientation of shed, cleaning of shed, use of disinfectants for cleaning of shed, provision of ventilation appropriate height of shed and proper drainage \& slope of floors was possessed by $33.75 \%, 17.92 \%, 37.08 \%$, $35.83 \%, 56.25 \%, 34.58 \%, 48.33 \%, 39.17 \%$ and $25.83 \%$ respectively in Punjab. In Punjab, the mean awareness about housing practices in goat farmers was $36.53 \%$ (Singh et al., $2020(\mathrm{e}))$. 
In Banka district in Bihar, most of the farmers utilized the state department of animal husbandry for getting information related to livestock farming (Kumar and Rao, 1999). Main limitations to effective goat health management in Bihar were an inadequate focus on preventive measures, lack of medicines and equipment in rural veterinary clinics and ignorance among the farmers (Dey et al., 2007).

In Punjab, the extension contacts, social participation, mass media exposure of most of the goat farmers were low to medium and farmers have not taken any formal training in goat farming. So, strong extension drives should be launched at door steps of goat farmers for more participation of goat farmers.

Main factor affecting adoption of correct practice by goat farmers was Unawareness followed by high cost, complexity of technology and unavailability of technology. This suggests the importance of organising more extension programme for goat farmers at their doorsteps (Singh, 2020).

It is clear from foregoing that Goat rearing plays a vital role in food and economic security of rural people, especially landless, marginal and small farmers. Goat not only provides employment to the rural poor, but it also acts as a security against the crop failure as an economic asset. However, the knowledge level of goat farmers is not up to mark. There is dire need to formulate goat farmer friendly knowledge enrichment drives and to work on the aspects of increasing economic return from goat farming system.

\section{References}

Alex, R., Cheemani, R. K. and Thomas, N. 2013. Returns and determinants of technical efficiency in small-scale Malabari goat production units in Kerala, India. Tropical
Animal Health and Production 45: 1663-68.

Arya, H. P. S. and Chander, M. 2000. Goat production by landless and small scale farmers in North Indian plains. In Proc. Seventeenth Sympo. Int. Farming Systems Asso. Lake Buena Vista, Florida, USA. Conference.ifas.ufl.edu/ifsa/ papers/a/a10.doc.

Birthal, P. S. and Taneja, V. K. 2006. Livestock sector in India: opportunities and challenges for small holders. In: Proceedings of Workshop on Smallholder livestock production in India: Opportunities and challenges 31 Jan - 1 Feb, 2006, Delhi, India.

Braker, M. J. E., Udo, H. M. J. and Webb, E. C. 2002. Impacts of intervention objectives in goat production within subsistence farming systems in South Africa. South African Journal of Animal Science 32: 185-91.

Chander, M. and Rathod, P. K. 2015. Livestock Innovation System: Reinventing public research and extension system in India. Indian Journal of Animal Science 85(11): 1155-63.

Devendra, C. 2001. Small ruminants: imperatives for productivity enhancement, improved livelihoods and rural growth: A review. Asian-Australian Journal of Animal Science 10: 1483-96.

Dandapat, A. and Choudhury, K. B. D. 2009. Socioeconomic profile, management practices and constraints of goat and poultry keeping in Tripura state, India. Indian Journal of Animal Production and Management 25: 99-102.

Debele, G., Guru, M., Hundessa, F. and Duguma, M. 2013. Assessment of farmers' management practices and factors affecting goats' production system in Adami Tulu Jido kombolcha district of East Shawa Zone Ethiopia. Agriculture and Biology Journal of North America 4(5): 520-26.

Gautam, M. 1998. 'Contribution of rural women in goat husbandry'. M.Sc. Thesis, IVRI, Izatnagar, India.

George, P. R., Ranganathan, T. T., Simon, S. and Pradeep, C. A. 2010. Knowledge of farm women of Wayanad district, Kerala about goat rearing practices Indian Journal of Animal Research 44 (1): 61-63. 
Koli, R. T. and Koli, S. R. 2016. Extent of adoption of goat farming technologies and problems faced by goat keepers in adoption of goat farming technology. Research Journal of Animal Husbandry and Dairy Science 7(1): 35-38.

Kumar, S., Rama Rao, C. A., Kareemulla, K. and Venkateswarlu, B. 2010. Role of Goats in livelihood security of rural poor in the less favoured environments. Indian Journal of Agricultural Economy 65(4): 760-81.

Kumar, S., Vaid, R. K. and Sagar, R. L. 2006. Contribution of goats to livelihood security of small ruminant farmers in semiarid region. Indian Journal of Small Ruminants 12(1): 61-66.

Kumar, S. and Jain, D. K. 2002. Economics of commercial goat farming under semiintensive system of management. Agricultural Economics Research Review. 13(2): 138-43.

Lalwar, V. S., Deoka, D. K., Nimase, K. G., Hale, R. R. and Mandakmale, S. D. 2009. Status of village goat management practices under home tract of Sangamneri goat. The Asian Journal of Animal Science 3(2): 134-37.

Lusweti, E. C. 2000. A survey of goat production in the developing areas of the North West province of South Africa. Short Communication. South African Journal of Animal Science 30: 34-35.

Lebbie, S. H. B. 2004. Goats under household conditions. Small Ruminant Research. 51(2): 131-36.

Jayashree, R., Jayashankar, M. R., Nagaraja, C. S., Satyanarayana, K. and Shrikrishna, I. 2014. Goat rearing practices in southern Karnataka. International Journal of Science, Environment and Technology 3(4): 1328-35.

Kumar, S. 2007. Commercial Goat Farming in India: An Emerging Agri-Business Opportunity. Agricultural Economics Research Review 20 (Conference issue): 503-20.

Kumar, S. and Deoghare, P. R. 2002. Goat rearing and rural poor: A case study in southwestern semiarid zone of Uttar Pradesh. Annals of Arid Zone 41(1): 79-84.

Mohan, B., Sagar, R. L. and Singh, K. 2009. Factors related to promotion of scientific goat farming. Indian Research Journal of Extension Education 9(3): 47-50.

Neupane, N., Neupane, H. and Dhital, B. 2018. A socioeconomic view of status and prospects of goat farming in rural areas of Nepal Journal of Institute of Agriculture and Animal Science 35: 1-8.

Peacock, C. P. 1996. Improving Goat Production in the Tropics. A manual for development workers. FARM-Africa/Oxfam, Oxford \{Original not seen: cited by Aziz M A. 2010. Present status of the world goat populations and their productivity Lohmann information 45 (2): 42-52\}

Peacock, C. P. 2005. Goats - A pathway out of poverty. Small Ruminant Research 60(1): 179-86.

Ramesh. 2009. 'Small Ruminant Farming Systems in Different Agro-Climatic Zones of Karnataka'. M.V.Sc. Thesis, IVRI, Izatnagar, India.

Rezvanfar, A., Moradnezhai, H. and Vahedi, M. 2007. Information needs of farm women related to dairy farming and home management in Ilam State of Iran. Livestock Research for Rural Development 19(8): 1518.

Roy, R. and Tiwari, R. 2017. Farmers' knowledge and adoption level on goat healthcare management practices in selected areas of India Bangladesh Journal of Animal Science 46(2): 95-101.

Sahlu, T. and Goetsch, A. L. 2005. A foresight on goat research Small Ruminant Research 60: 7-12.

Satyanarayan, K. and Jagadeeswary, V. 2010. A study on knowledge and adoption behaviour of livestock farmers Indian Journal of Animal Research 44(2): 100 -06.

Sharma, M. C. and Jindal, S. K. 2008. Prospects of goat production in India. Compendium of lectures, ICAR sponsored winter school November 25 to December 15, 2008 on Recent advances in improvement of productive and reproductive efficiency of goats through physiological and nutritional interventions, CIRG, Farah, Mathura, U. P.: pp 13-18

Singh, K. P., Dixit, S. P., Singh, P. K., Tajane, K. R., Singh, G., Ahlawat, S. P. S. 2009. Economics of goat farming under 
traditional low input production system in north Gujarat region of India. Indian Journal of Animal Sciences 79(9): 948-51.

Singh, M. K., Ramachandran, N., Chauhan, M. S. and Singh, S. K. 2018. Doubling rural farmers' income through goat farming in India: prospects and potential. Indian Farming 68(01): 75-79.

Singh, R P. 2002. Contribution of goats in tribal economy- A micro study of Ranchi, Jharkhand. Rural India, pp. 2-5.

Singh, S. 2020. Training need assessment of Goat farmers in Punjab M.V.Sc. Thesis, Guru Angad Dev Veterinary and Animal Sciences University, Ludhiana, India.

Singh, S., Kasrija, R., Chawla, P., Singh, J., and Wakchaure, N. 2020 (a). Assessment of Knowledge Level of Goat Farmers about Feeding Practices in Punjab. International Journal of Livestock Research, 10(4), 5559. doi: http://dx.doi.org/10.5455/ijlr.20 200114074637

Singh, S., Kasrija, R., and Singh, P. 2020 (b) Determination of knowledge level of goat farmers about breeding practices in Punjab Journal of Entomology and Zoology Studies 8 (2):198-200.

Singh, S., Kasrija, R. and Singh, P. 2020 (c). Reckoning Health Care and Management Practices Knowledge of Goat Farmers of Punjab. International Journal of Current Microbiology and Applied Sciences 9(02): 2866-2871.

doi: https://doi.org/10.20546/ijcmas.2020.902.3 26.

Singh, S., Kasrija, R., Singh, P., Singh, J. and Singla, M. 2020 (d). An Appraisal of Demographic Parameters of Goat Farmers of Punjab. International Journal of Current Microbiology and Applied Sciences 9(01): 136-144. doi: https://doi.org/10.20546/ijcmas.2020.901.0 15.

Singh, S., Kasrija, R., Singh, P. and Singla, M. 2020 (e) Awareness appraisal of goat farmers of Punjab about housing practices The Pharma Innovation Journal 9(1): 354-356.

Singh, S. P., Singh, A. K. and Prasad, R. 2011. Economics of Goat Farming in Agra District of Uttar Pradesh Indian Research Journal of Extension Education 11(3): 3740.

Tanwar, P. S., Vaishanava, C. S. and Sharma, V. 2008. A study on socio-economic aspects of goat keepers and management practices prevailed in the tribal area of Udaipur district of Rajasthan. Indian Journal of Animal Research 42(1): 71-74.

Yadaw, K. N. and Sharma, M. L. 2012. Adoption and adoption gap of Goat keepers towards recommended Goat rearing practices. Indian Research Journal of Extension Education 12(2): 77-80.

\section{How to cite this article:}

Sukhwinder Singh, Rajesh Kasrija and Parminder Singh. 2020. An Insight of Present Goat Farming Situation- A Review. Int.J.Curr.Microbiol.App.Sci. 9(08): 3021-3029. doi: https://doi.org/10.20546/ijcmas.2020.908.341 